\title{
Efficient paste mix designs using new generation backfill admixtures - perception versus reality
}

\author{
Fabian Erismann \\ Sika Tunneling and Mining, Switzerland \\ Martin Hansson \\ Sika Tunneling and Mining, Sweden
}

SUMMARY: Backfilling mined out stopes with cemented paste has become the standard in most modern, long-hole stoping- and cut- and fill operations globally. The implementation of large scale paste production plants and efficient underground paste reticulation systems contributed significantly to maximised ore extraction, higher levels of mine-scale, geotechnical stability, larger degree of automation and last but not least to a more conscious management of mine processing waste. However, paste backfilling comes at a cost.

Binder costs alone amount to $70-80 \%$ of total operating costs of paste plants depending on the strength requirements and characteristics of tailings used for backfilling and it is not uncommon that underground paste filling contributes up to $20 \%$ of the overall cost structure of an underground operation. With a view towards improving the paste mix designs and keeping cement consumption under control, new generation paste backfill admixtures have been developed over the past years. The mine backfill industry can be compared to the concrete industry 40 years ago, when high performance admixtures started to emerge for land mark projects, where exceptionally high concrete qualities and specific, fresh concrete properties were required (Aitcin and Wilson, 2015). These high range water reducers quickly transformed the construction industry and pushed concrete applications to new, previously unknown limits.

This paper intends to give an overview of the reality of admixtures in the mine backfill industry and their performance and justification in modern paste backfill plants. Data from different paste plants around the globe has been compiled for this study, covering different deposit types, strength requirements and paste mix designs. The study illustrates the powerful effect paste backfill admixtures can have on standard, paste mix designs and their potential to reduce binder consumption substantially by remaining within the required strength- and workability limits of the paste to improve the overall cost structure of backfill operations.

Keywords: paste fill, admixtures, binder, optimization, mining

\section{INTRODUCTION}

High range superplasticisers with the ability to significantly reduce water out of a given concrete mix, while maintaining the workability but strongly influence the strength- and durability characteristics of concrete, have been introduced to the global construction industry by the end of the 1990's (Ramachandran et al., 1998). Today, the fundamental reason to develop and utilise such superplasticisers in nearly every day mass produced concrete is the strong and lasting effect of a lower water content, or lower water to binder ratio to be more specific, on concrete. As an example: In order to 
produce a $25 \mathrm{MPa}$ concrete it is necessary to use around $300 \mathrm{Kg}$ of cement without the use of an admixture. In contrast, when a $75 \mathrm{MPa}$ concrete is produced, $450 \mathrm{Kg}$ of cement is needed plus some litres of superplasticizer to reduce the water to binder ratio. Hence, while using only 1.5 times as much cement, the strength of the concrete triples (Aitcin and Flatt 2016).

Similar to concrete, cemented paste is a cementitious system too, sharing similarities with concrete. The fact that reducing the water to binder ratio in concrete has a positive effect on strength development at a given cement content, is even more pronounced in water-saturated or a water-oversaturated system like a cemented paste, where the water to binder ratio is of an order of magnitude larger than in concrete. Reducing water in such systems has a very strong effect on the strength development of the paste fill (Erismann et al. 2016).

Today, this simple principle, which is illustrated in Figure 1 (left hand side), has only partly found its way into the mine paste backfill industry, where the use of such admixtures is not standardised and very often, no admixtures are used at all, in order to improve the cost performance of paste backfill plants (Erismann et al. 2017). Figure 1 (right hand side) illustrates that oversaturated paste mixes of water to binder ratios of 5 and higher have a poor correlation between the added amount of binder and strength development. This obviously represents a challenge in meeting strength requirements in wet mixes.

This paper should help to address this shortcoming by presenting three case studies from mines where admixtures are used and have a very positive effect on the quality and performance of the backfill system. The three mine sites are completely unrelated to each other from a geographical, mineralogical, structural- and ore forming process point of view. By choosing such different cases, the authors would like to emphasize how important a proper admixture selection is by looking at the mineralogical and physical footprint of these deposits and hence the generated tailings which are the base of the produced backfill mix.

By far the most common goal while using admixtures is to increase the solid content of the fill, which in turn should have a positive effect on strength development as illustrated in Figure 1. As yield stress is positively correlated with the solid content of the fill, e.g. the higher the solid content, the higher the yield stress (Silva 2017), increasing the solid content of the fill is expected to have an effect on the pumping pressure within the reticulation system of the mine. However, actual pressure data from the mines could show that this is not necessarily the case.
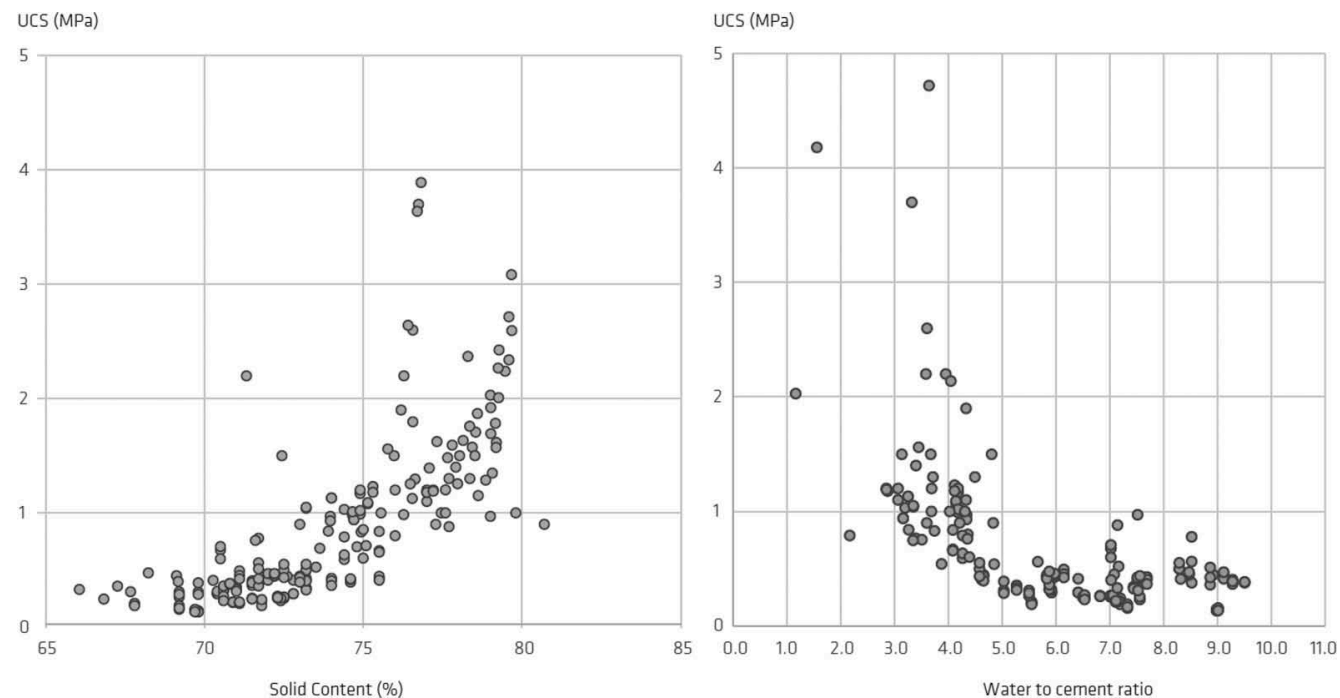

Figure 1. Left hand side: Paste solid content versus uniaxial compressive strength. Data from several paste plant projects. Right hand side: Relationship of water- to cement ratio and the uniaxial compressive strength. 
In combination with admixtures, a pressure reduction can be achieved while strongly increasing the solid content at the same tame. This will be illustrated using the three case studies.

\section{METHODOLOGY}

For this paper, data from three different paste plants have been used over a period of three years. The mines where these paste plants are installed are located in North America, West Africa and Europe and are hosted by three different deposit types. The mine located in North America is a typical Carlin-type deposit. The mine in Europe is widely referred to as a SEDEX (Sedimentary Exhalative) type deposit and the one on West Africa a gold deposit of Orogenic type which is very common in this part of Africa (Partington and Williams 2000). Despite the differences in terms of ore-forming processes, alteration mineralogy, mineralization type and host lithology, these deposits also share similarities to a certain extent.

Particle size distribution as well as full phase mineralogical composition analyses were conducted at the Sika Technology laboratories in Zürich, Switzerland. Mineralogical analytics were done using scanning electron microscopy (SEM) to identify and confirm major and minor mineral phases and then quantify them using X-ray diffraction.

All mines utilise large tonnages of cemented paste fill and have different requirements in terms of early and final strength development as well as workability of the fill. Strength of the fills was tested according to the mine's specifications, usually testing the strengths after 7 days, 14 days, 28 days and 56 days. As common in many mines, workability is tested using standard concrete slump cones to measure the slump of the produced paste. Workability of the paste is related to yield stress and measuring the slump has proven to be a viable method to get an indication of the actual yield stress of the paste (Silva 2017). These workability limits often range in the 7-10 inch slump range (Erismann et al. 2017). Measuring the slump and final flow table spread is appropriate for an indication of the actual yield stress (Silva 2017), this test method remains the most common at mine sites. Special attention was also given to the behaviour of pumping pressure, both on surface and underground where possible and where the reticulation system is equipped to measure such data.

\section{ADMIXTURE SELECTION}

Selecting the right admixture for a certain paste is crucial to optimise the cost performance of a paste backfill system (Erismann et al. 2017). This can be illustrated based on the chosen ore deposit types described in Figure 2, where the simplified geological sections are shown. These deposits show the following characteristics:

A) Sedimentary Exhalative polymetallic (lead, zinc, silver, copper) deposit in Europe. These deposits are derived from an ancient, sub-seafloor, hydrothermal vent that deposited metals upon cooling and redox reactions of hydrothermal brines in contact with seawater on - or close to the seafloor (McKibben et al 1997). Usually, there is a distinct footwall alteration associated with these deposits. In this case, it is an intense potassic alteration, rich in $\mathrm{Na} 2 \mathrm{O}$ and $\mathrm{K} 2 \mathrm{O}$ with associated minerals such as Muscovite and Biotite.

B) Orogenic, shear-hosted gold lode deposits: This deposit type is a major host for gold globally. In this particular case the gold bearing shear zone is defined by a highly strained and brecciated, narrow zone that is heavily altered at either side of the shear including alteration products such carbonate, silica, albite, pyrite, chlorite and hematite.

C) Carlin-type, limestone/dolomite hosted gold deposit: This deposit type is characterised by the calcareous dominated host lithology and the distinct alteration features that can directly be linked to hydrothermal fluids responsible for the introduction of gold alongside alteration features such as carbonate dissolution, argillic alteration and silicification (Hausen and Kerr 1968, Radtke 1980, Bakken and Enaudi 1986). 

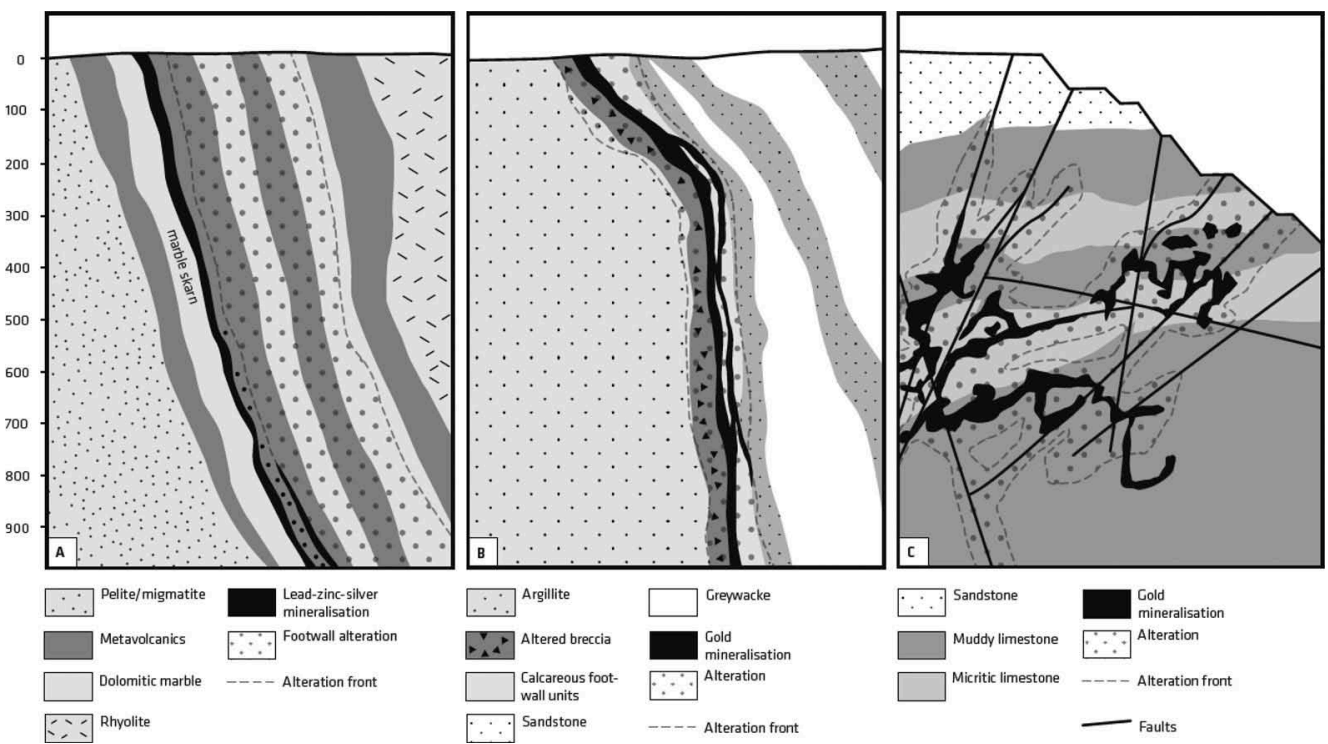

Figure 2. Simplified geological sections showing main lithological units as well as extent of alteration.

The alteration mineralogy of these systems is important with a view towards the effectiveness of the used admixture. The effectiveness can be fairly easy tested by performing yield stress measurements (using a viscometer or rheometer) or by measuring the flow table spread of different admixtures with a certain paste. A strong rheological impact on a paste can usually be linked to a strong plastification of the paste and hence a large increase of the flow table spread, slump values as well as much lower yield stresses for both rheometer and viscometer measurements. This selection process resulted in three different admixture types that were used for these deposits. The exact selection criteria will not be described in this paper, however, the presence of phyllosilicates in all three deposits as well as the dominating calcareous phases in deposit $\mathrm{B}$ and $\mathrm{C}$, are strongly influencing the compatibility of certain polymers for these specific tailings.

An overview of the mineralogical composition and hence the overall chemistry of the deposits is shown in Table 1, where percentage composition for a certain mineral phase is given.

Particle size distribution of the three different mine tailings is shown in Figure 3. Mine A has the coarsest tailings and mine $\mathrm{C}$ the finest sieve fractions with $80 \%$ of tailings passing the $50 \mu \mathrm{m}$ fraction.

\section{INFLUENCE OF ADMIXTURES ON PASTE - RESULTS}

\subsection{Solid content}

Once a suitable admixture has been identified for a paste backfill project, the reaction of the paste plant, once the admixture is dosed into the batched- or continuous filling process, is usually a strong decrease of torque in the twin shaft mixer. This decrease in torque is indirectly measured by the decrease in energy, the mixer draws to mix a certain volume of paste contained in the mixer. Modern paste plants have a fixed energy range the mixer is supposed to work in, in order to provide a paste consistency that is suitable to pump through the paste reticulation system. Once the energy draw falls below this pre-defined limit, water addition is automatically reduced. The same is the case once energy levels increase above the pre-defined limit. If this is the case, water is added to the mix in order to bring the viscosity of the paste into the desired window. As admixtures usually strongly reduce the yield stress of paste, mixing is usually easier once the admixture is added, the energy level drops, water is reduced and the solid content goes up. 
Table 1. Mineralogical composition of the three deposits. Values indicate the volume percentage of contained minerals. Alteration minerals are indicated in dark grey. Minerals that might originate from the original host lithology as well as an alteration product are indicated by the light grey shading.

\begin{tabular}{|c|c|c|c|c|}
\hline & & A & B & C \\
\hline & & $\begin{array}{l}\text { SEDEX } \\
\text { Type }\end{array}$ & $\begin{array}{l}\text { Orogenic } \\
\text { Type }\end{array}$ & $\begin{array}{l}\text { Carlin } \\
\text { Type }\end{array}$ \\
\hline Quartz & $\mathrm{SiO}_{2}$ & 31.4 & 25 & 51.5 \\
\hline Sulphides & $\begin{array}{l}\mathrm{FeS}_{2}, \mathrm{CuFeS}_{2}, \mathrm{FeS}, \mathrm{PbS}, \mathrm{ZnS}, \\
\mathrm{FeAsS}\end{array}$ & 1.9 & 1.3 & \\
\hline Muscovite & $\mathrm{KAl}_{2} \mathrm{AlSi}_{3} \mathrm{O}_{10}(\mathrm{OH})_{2}$ & 8 & & 11.9 \\
\hline $\begin{array}{l}\text { Biotite } \\
\text { Chlorite }\end{array}$ & $\begin{array}{l}\mathrm{K}(\mathrm{Mg}, \mathrm{Fe})_{3} \mathrm{AlSi}_{3} \mathrm{O}_{10}(\mathrm{OH})_{2} \\
(\mathrm{Fe}, \mathrm{Mg}, \mathrm{Al}, \mathrm{Zn})_{6}(\mathrm{Si}, \mathrm{Al})_{4} \mathrm{O}_{10}(\mathrm{OH})_{8}\end{array}$ & $\begin{array}{l}10 \\
7.2\end{array}$ & $\begin{array}{l}1.3 \\
5.9\end{array}$ & \\
\hline $\begin{array}{l}\text { Calcite } \\
\text { Dolomite }\end{array}$ & $\begin{array}{l}\mathrm{CaCO}_{3} \\
\mathrm{CaMg}\left(\mathrm{CO}_{3}\right)_{2}\end{array}$ & & $\begin{array}{l}1.4 \\
15.7\end{array}$ & $\begin{array}{l}15.8 \\
15.7\end{array}$ \\
\hline $\begin{array}{l}\text { Orthoclase } \\
\text { Albite } \\
\text { Diopside (Mg-rich } \\
\text { Pyx) } \\
\text { Cordierite }\end{array}$ & $\begin{array}{l}\mathrm{KAlSi}_{3} \mathrm{O}_{8} \\
\mathrm{NaAlSi}_{3} \mathrm{O}_{8} \\
\mathrm{CaMgSi}_{2} \mathrm{O}_{6} \\
\\
\mathrm{Mg}_{2} \mathrm{Al}_{4} \mathrm{Si}_{5} \mathrm{O}_{18}\end{array}$ & $\begin{array}{l}22.8 \\
14.2\end{array}$ & 47.8 & \\
\hline $\begin{array}{l}\text { Hematite } \\
\text { Illite }\end{array}$ & $\begin{array}{l}\mathrm{Fe}_{2} \mathrm{O}_{3} \\
(\mathrm{~K} 0.65) \mathrm{Al}_{2}\left(\mathrm{Si}_{3} \mathrm{Al} 0.65\right) \mathrm{O}_{10}(\mathrm{OH})_{2}\end{array}$ & & 1.7 & $\begin{array}{l}3 \\
1\end{array}$ \\
\hline Bassanite & $\begin{array}{l}\mathrm{CaSO}_{4} 1 / 2 \mathrm{H}_{2} \mathrm{O} \\
\text { Admixture type }\end{array}$ & A & $\mathrm{B}$ & $\begin{array}{l}7.1 \\
\mathrm{C}\end{array}$ \\
\hline
\end{tabular}

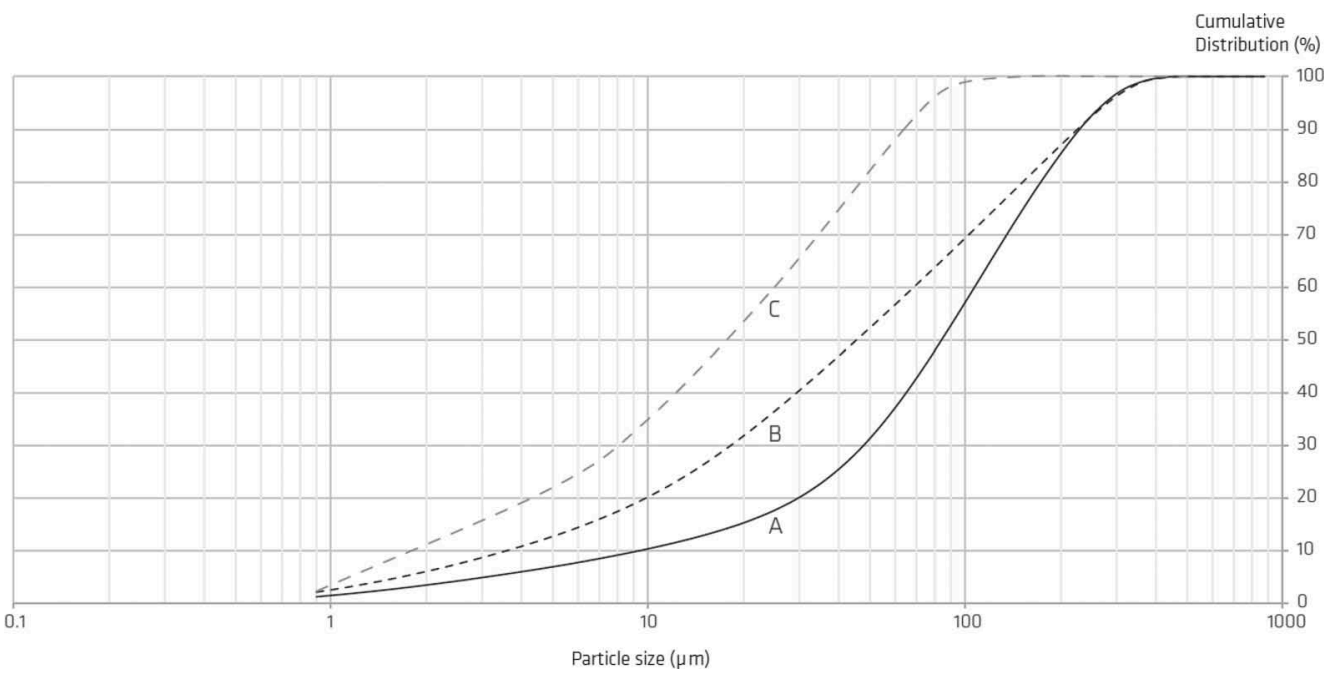

Figure 3. Particle distribution of the three mine tailings used for this study.

This fairly quick interaction is illustrated in Figures 4, 5 and 6 where parameters such as water addition and line pressure (both on surface and underground) as well as the admixture dosage and solid content are plotted along the time axis. It is easy to observe that admixture dosage and water addition to the mix strongly correlates. The more admixture is dosed into the system, the higher the reduction of added water, in some cases the water addition stops entirely and the solid content of the paste is approaching the solid content of the filter cake. Workability 


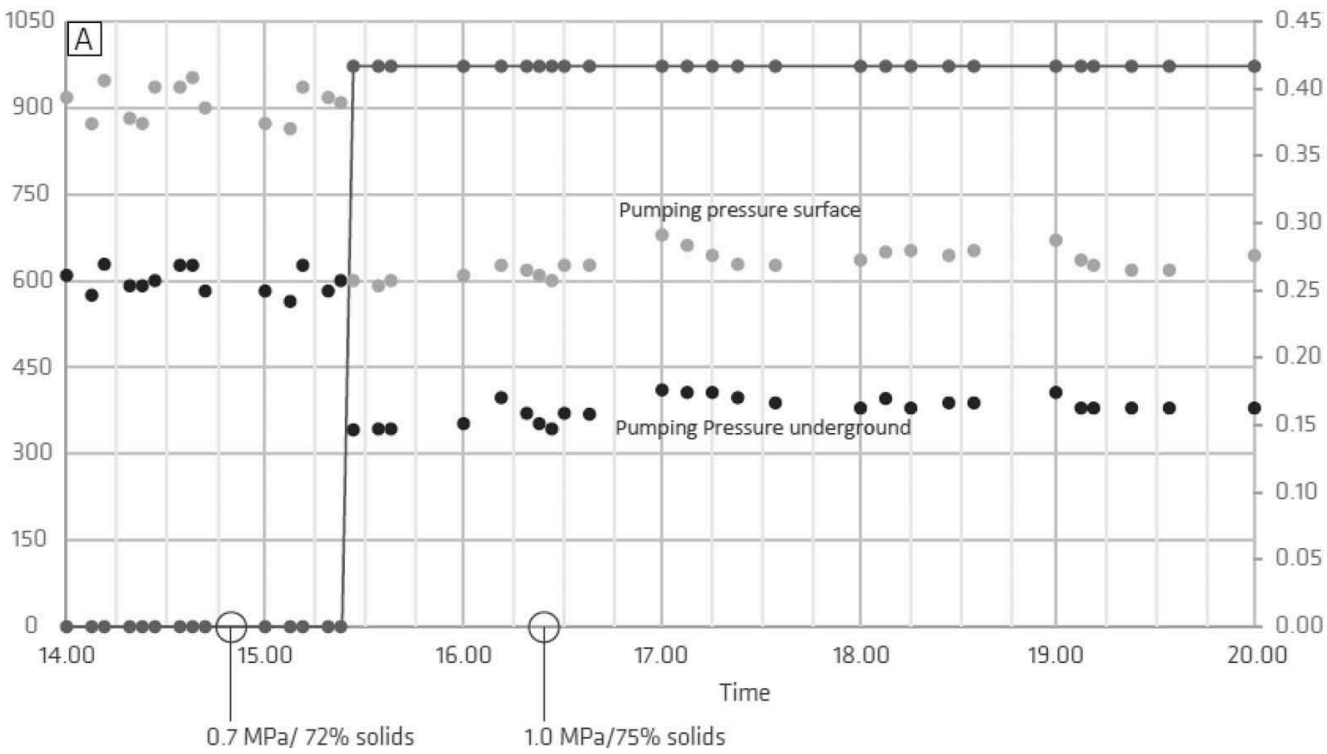

Figure 4. Development of pumping pressure for the SEDEX deposit (project A) for paste line pressure on surface and underground, before- and after the dosing of admixtures. Results for a paste mix containing $6 \%$ cement.

of the paste is often measured using a standard slump test at most mine sites. In all three sites, this slump test has been used to track workability of the paste throughout the observation span.

Remaining within these slump limits, which is usually between 7-10 inches on a standard concrete slump cone, was a requirement of all sites and was fulfilled at all times.

\subsection{Pumping pressure}

Once the admixture is added to a paste mix, the yield stress of the mix is usually decreasing strongly. As a response of the system, the water addition is subsequently reduced from the mix to reach the desired properties of the paste in terms of strength development and cement content, yield stress will increase again which is a well described correlation between the solid content of a slurry and its yield stress (Silva 2017, Sofra 2017).

Test results from large scale applications with admixture, in the three described paste plants vary, but most data recorded showed stable line pressure or decreasing line pressure after the plant reached a new equilibrium with a steady admixture dosage. The Admixture dosage usually range from 0.4 to $2 \%$ by weight of cement. This decrease in pressure can be nicely observed in Figure 4, 5 and 6 . In all projects, the pressure actually decreases both on surface and underground, with increasing admixture dosage, despite increasing the solid content. Pressure spikes do occur once admixture dosing starts and the plant reacts on the lowered yield stress which is indicated by the lower torque value of the mixer with instant water reduction. These pressure spikes during the start-up phase are most likely related to the insufficient regulation of water addition/ reduction into the mixer. This is discussed in more detail during the discussion of this paper.

\subsection{Strength}

Strength development of the paste with increasing solid content is very favourable, both in terms of the early strength development (after a few days) as well as the final strength after 28 and 56 days. Such strength gains allow for strong cement reduction in the fill to fulfil the designed strength requirements of the fill. Strength results for different cement contents with- 


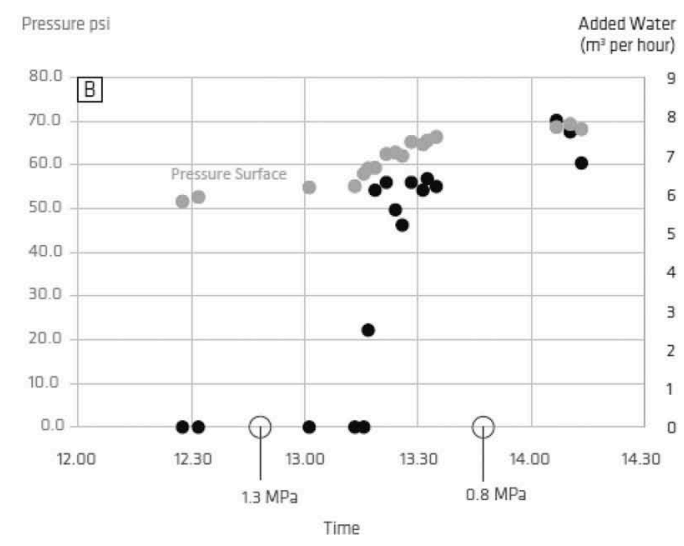

Paste Solid Content (\%)
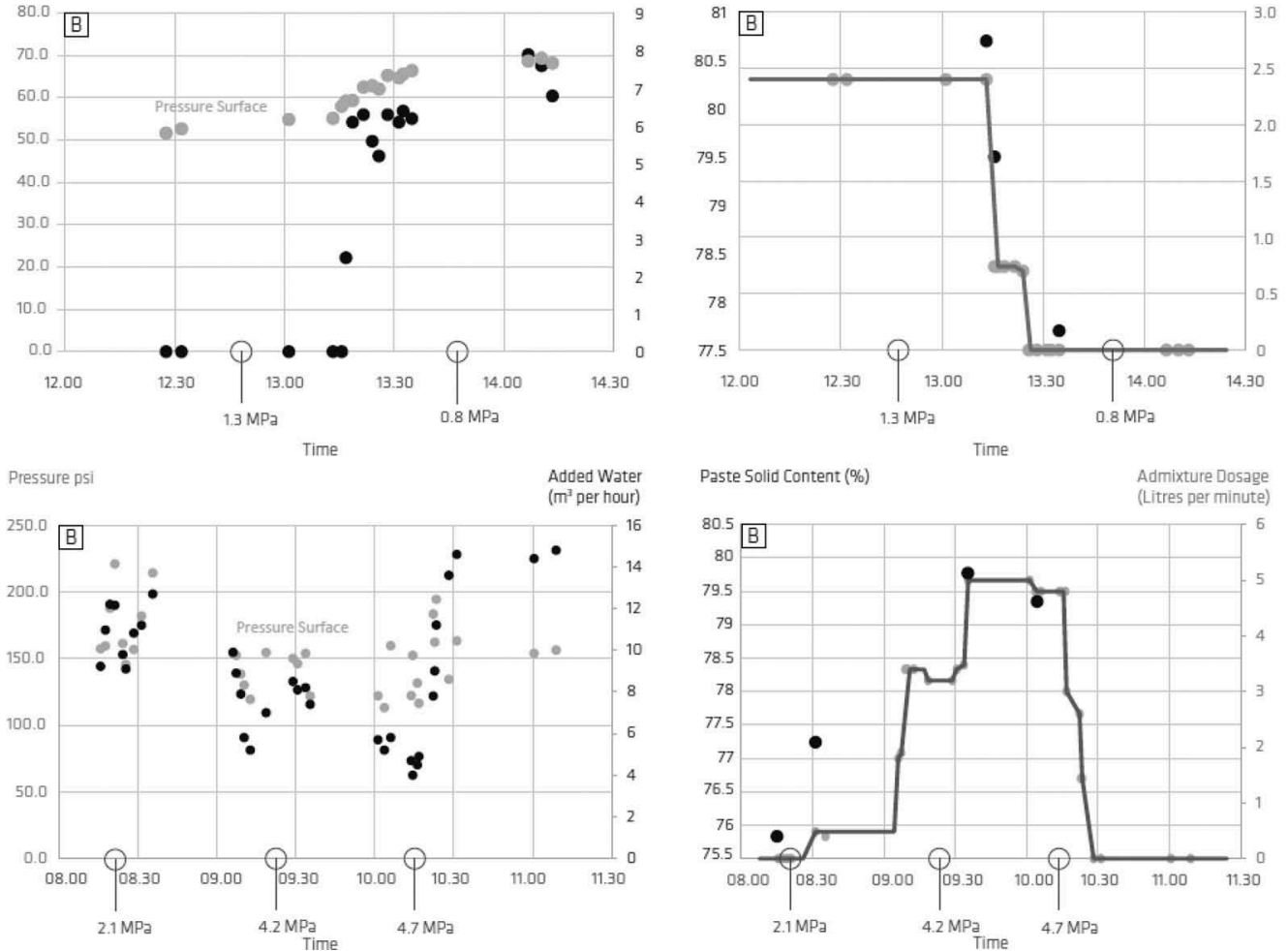

Figure 5. Development of pumping pressure on surface for the Orogenice Gold project (project B) with- and without dosing of admixtures. Results for a paste mix containing 5\% cement (upper diagram) and $12 \%$ cement (lower diagram).
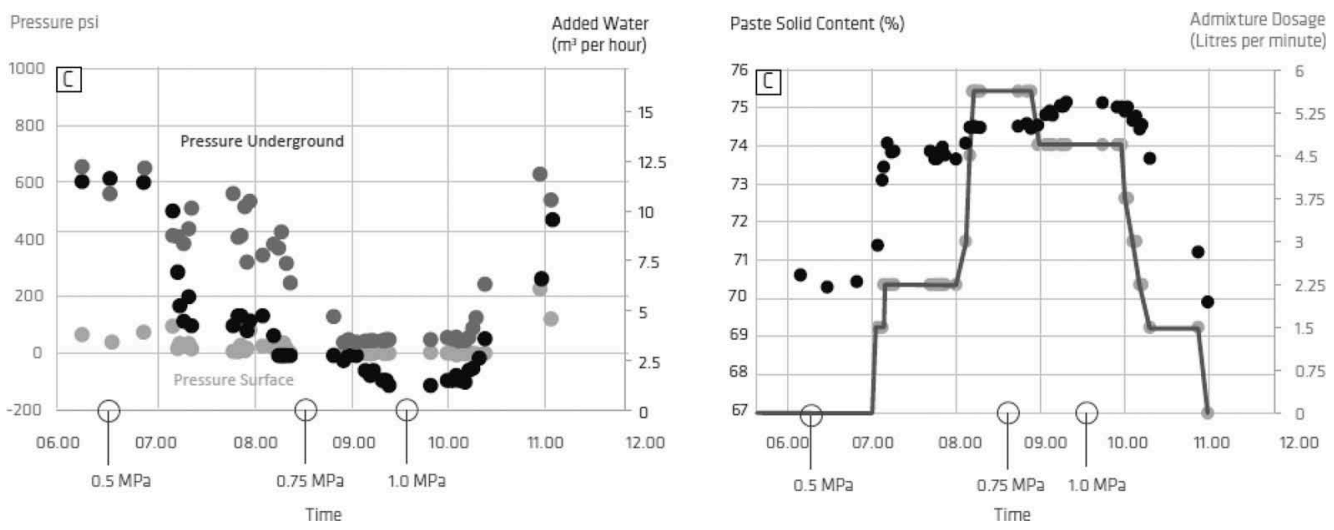

Figure 6. Development of pumping pressure on surface for the Carlin type Gold project (project C) with- and without dosing of admixtures. Results for a paste mix containing $8 \%$ cement.

and without admixtures are shown in Figure 7. The cement reduction potential observed in the described projects range from $20-50 \%$.

Strength loss over time has been frequently observed in paste operations. This problem has not been observed for any of the three described projects and is not expected long term either, 


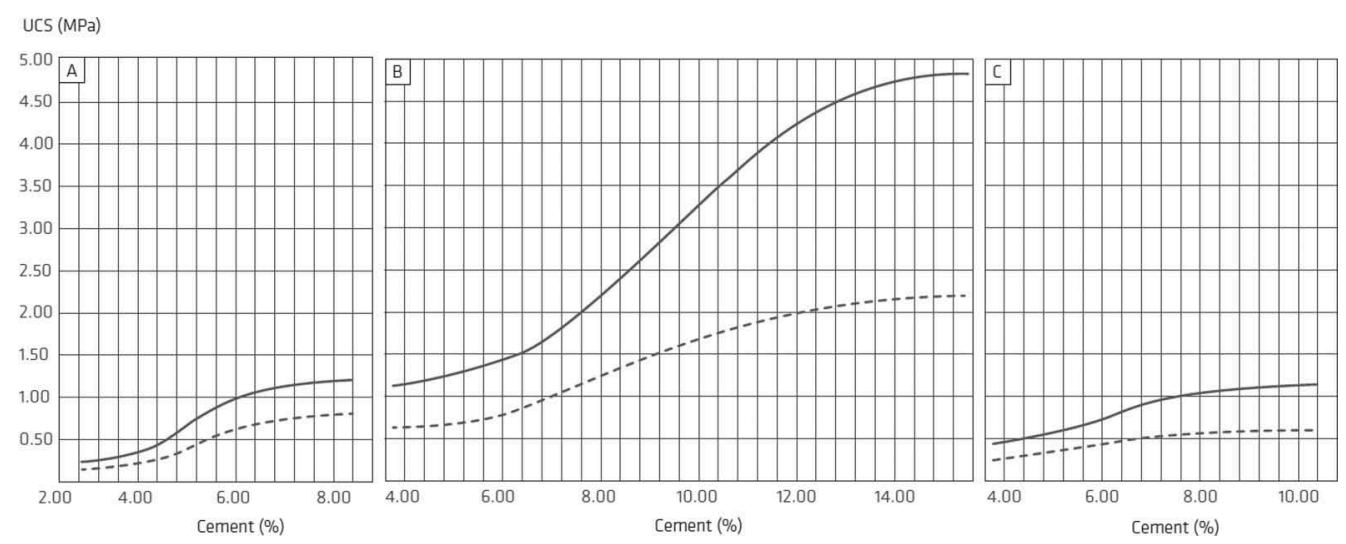

Figure 7. Strength results for project A, B and C for different cement contents in the paste fill. Dotted line displays results without admixtures, solid line the results with the use of admixtures.

as they have very low total sulphide content in the tailings and hence low $\mathrm{SO} 4^{2-}$ charges in the processing water. Dissolved SO4 ${ }^{2-}$ can have a strong effect on long term strength of the paste fill especially in fills containing a large proportion of sulphide minerals. Elevated $\mathrm{SO}_{4}^{2-}$ values in the pore water of the fill has a strong negative effect on long term strength of a cemented paste fill. Reduced water values in the fill will partly mitigate but no stop this issue.

\section{DISCUSSION}

The effect of admixture dosing into the paste stream showed to have a strong influence on a range of properties of the produced paste. High water to binder ratios in paste designs are common and water to binder ratios above 5 represents a challenge to achieve the needed strengths for a certain paste fill. This is mainly due to the oversaturated properties of such fills and the associated, limited strengths values even at high cement additions. Even in such water rich mixes, admixtures might still help as the dispersion force of cement and other particles in such a system is significantly increased when using admixtures (Lewis et al. 2000).

As the solid content of a paste mix is the driving factor for strength development at a given cement content, the ability of a suited admixture to strongly reduce yield stress of a paste is providing the precondition to reduce the water content of the fill. However, maintaining the workability of the paste and remaining within the pumping pressure limits of the reticulation system of the mine is critical when using admixtures. These workability limits were tracked at all three sites using a standard concrete slump cone to measure the slump of the paste mix continuously.

Despite the fact that the solid content was increased in all of the described cases, slump values tended to be elevated throughout the observation period, which indicates, that water could be withdrawn further. In two of the three plants, water addition to the mixer was reduced to almost zero with no further water reduction potential. Hence, the potential to increase the solid content and strength further reached the limit, unless improvements are made at the dewatering units (cone thickeners, vacuum disc filters) to produce a more dry filter cake. In two of the three cases described in this paper, the admixture overcompensates the effect, the solid content increase has on the line pressure of the reticulation system with pressures dropping well below the limits that have been observed prior to the addition of admixtures. This can be mainly related to the detrimental effect, excessive water has on a pumped paste mix. An oversaturated paste tends to segregate and free water is leading to elevated pressure levels compared with mixes that contain less water.

Pressure spikes have been recorded in all of the described operations. These pressure spikes were mainly related to the time period when the admixture dosage just started. This reflects the strong- and almost instantaneous impact the admixture has on the yield stress of the paste 
mix, which triggers immediate reduction of added water to the mixer. As this water addition is often controlled not sensitive enough (poorly controlled valves) and the system tends to overmitigate changes of the mixer torque value, water might be withdrawn too quickly, causing short term pressure spikes. An example from case A: The mixer release time to the feed-hoper of the piston pump is linked to a certain paste viscosity which is, again, linked to the energy draw of the mixer. As admixtures lead to a strong fall-off of mixer energy, these release times were triggered much faster causing the hoper fill levels to rise and the pump to pump faster, which resulted in an increase of paste line pressure. This side effect was solved by fixing the hoper release time that resulted in a continuous pumping speed.

Strength gains across the described cases were significant and material cement reductions could be achieved with all projects. Cement reduction compensates well for the additional cost of the admixture and has a very positive effect on the overall cost performance of the paste fill system. Furthermore, strength development is faster due to better, more rapid and complete cement hydration which allows for faster stope cycle times and the fill efficiency rate increases as the cubic meter of fill contains a higher solid content and less water. Furthermore, as cement consumption is among the largest driver for $\mathrm{CO}_{2}$ in underground mining operations, cement reduction in the paste fill will materially improve this important emission balance.

\section{CONCLUSION}

Paste backfill admixtures proved to have a powerful effect on paste mixes once a suitable admixture has been identified based on the physical and chemical properties of tailings. Admixtures are well suited to upgrade paste mix designs by increasing the solid content of the mix that usually goes hand in hand with higher achieved strength at the same binder content. Oversaturated fills with water to binder ratios of higher than 5 represents a challenge for a paste operation as elevated binder contents will not really improve the strength anymore.

The effectiveness of admixtures increases strongly with the ability of paste plants to produces a dry filter cake of around $80 \%$ solids. Once the capacity of the dewatering units such as cone thickeners and filters are reached, admixtures can only reduce the amount of added water to the mix until water addition stops entirely.

All three cases presented in this paper showed strong cement reduction potential after admixtures had been implemented. Cement reduction potential can be as high as $20-50 \%$ of total cement used. Pumping pressures remained constant or were reduced despite the much increase solid content of the paste mixes. The cost performance of paste plants can be greatly improved by using latest admixture technology and by evaluating a well suited admixture. The overall economics strongly depend on available cement prices, admixture effectiveness and dosage and the ability of the paste plant to provide a good quality and dry filter cake.

\section{BIBLIOGRAPHY}

Aitcin, P.C. and Flatt, R. Science and Technology of Concrete Admixtures. 2016 Cambridge: Woodhead Publishing, pp. xxi

Aitcin, P.C. and Wilson, W. 2015. The Sky's the limit. Concrete International 37(1), pp. 53-58

Bakken, B.M. and Einaudi, M.T., 1986, Spatial and temporal relations between wall rock alteration and gold mineralization, main pit, Carlin gold mine, Nevada, U.S.A.: in Macdonald, A.J., ed., Proceedings of Gold '86, an International Symposium on the Geology of Gold: Toronto, Canada, pp. 388-403.

Erismann, F.J, Kurz, C. and Hansson, M. 2016. The Benefits of Incorporating Admixtures into Mine Paste Backfill. $19^{\text {th }}$ International Seminar on Paste and Thickened Tailings: Proceedings of the Conference on Paste and Thickened Tailings. Santiago, Chile 5-8 July 2016. pp. 76-86

Erismann, F.J, Kurz, C. and Hansson, M. 2017. Translating Paste Backfill Admixture Results from the Laboratory into the Field. 20th International Seminar on Paste and Thickened Tailings: Proceedings of the Conference on Paste and Thickened Tailings. Beijing, China 15-18 June 2017. pp. 190-198 
Hausen, D.M., and Kerr, P.F., 1968, Fine gold occurrence at Carlin, Nevada, in Ridge, J.D., ed., Ore Deposits of the United States, 1933-1967, The Graton-Sales Volume: The American Institute of Mining, Metallurgical, and Petroleum Engineers, inc., New York, Ch. 46, pp. 908-940.

Lewis, J.A., Matsuyama, H., Kirby, G. and Morissette, S., 2000. Polyelectrolyte Effects on the Rheological Properties of Concentrated Cement Suspensions. J. Am. Ceram. Soc., 83 [8] pp. 1905-13

McKibben et.al. 1997 - McKibbe, M.A. and Hardie, L.A. 1997, Ore-forming brines in active continental rifts: In H.L Barnes (ed.), Geochemistry of hydrothermal ore deposits. Wiley Interscience, pp.877-930

Partington. C.A and Williams, P.J. 2000. Proterozoic lode gold and (iron)-copper-gold deposits: a comparison of Australian and global examples. Reviews in Economic Geology, 13, 69-101.

Radtke, A.S., Rye, R.O., and Dickson, F.W., 1980, Geology and stable isotope studies of the Carlin gold deposit, Nevada: Economic Geology, v. 75, pp. 641-672.

Ramachandran, V.S., Malhotra, V.M., Jolicoeur, C., Spiratos, N., 1998. Superplasticizers. Properties and Applications in Concrete. Materials Technology Laboratory, CANMET, Ottawa, Canada.

Silva, M., Contribution to Laboratorial Determination of Rheological Properties of Paste Backfill, Zinkgruvan and Neves-Corvo Case Studies. 2017. Master Thesis, IST Press, 82 pp. Technico Lisboa, Lisbon, Portugal.

Sofra, F. 2017. Rheological Properties of Fresh Cemented Paste Tailings. Yilmaz, E. and Fall, M. (eds) Paste Tailings Management, Springer, Cham, pp. 33-57. 